\title{
The Analysis of Fundamental Movement Skill in Primary School Student in Mountain Range
}

\author{
Didik Rilastiyo Budi*, M. Nanang Himawan Kusuma, \\ M. Syafei \\ Universitas Jenderal Soedirman. \\ Jalan Dr. Soeparno Karangwangkal 53123 Purwokerto, \\ Indonesia \\ *didik.rilastiyo.budi@unsoed.ac.id
}

\author{
Mesa Rahmi Stephani \\ Faculty of Sports and Health Education \\ Universitas Pendidikan Indonesia \\ Jalan Dr. Setiabudhi No.229 Bandung 40154, Indonesia
}

\begin{abstract}
This study aims to analyze the fundamental movement skill in primary school student. The method using descriptive method and the amount of sample is $\mathbf{2 0}$. Fundamental movement skill measure through TGMD-3. The data analyzed by percentage method. 50 percent children in lack level. And only 20 percent in good category. The effect of demography is discussed in this article. The low quality of basic motion in elementary school students is because students have not been taught multilateral motion skills, and most teachers do not know the importance of mastering multilateral motion based on fundamental movement skills for children, so they tend to teach sports skills to students in physical education classes.
\end{abstract}

Keywords-acute respiratory tract infection; smoking; pneumonia; standard deviation nutritional status (Z-score)

\section{INTRODUCTION}

Conceptually, child development is based on three domains, namely psychomotor, cognitive and affective. The psychomotor domain consists of physical and motor abilities based on biological (growth) and motoric (functional) processes. Manna explain that Growth and physical maturation are dynamic processes encompassing a broad spectrum of cellular and somatic changes. The most obvious signs of physical growth are changes in overall body size [1].

Psychomotor development is all the basic abilities in functioning motor skills. In psychomotor development is divided into three parts, namely motor development and development and development of motoric perception and physical fitness

Motor physical development in children can be marked by physical growth which includes increased body weight, height, head and muscle circumference. Generally, the body of a boy is taller and heavier and has a lot of muscle in each kilogram of body weight. While girls have tissued more fat. Gallahue explain that development is the continuous process of change over time beginning at conception and ceasing only at death. motor development, therefore, is progressive change in movement behavior throughout the life cycle [2]

Then regarding the development experienced by children in the life cycle, Gallahue classifies children into two categories, namely early childhood (3-8 years) and later childhood (8-12 years) to see the difference in growth and development [2] They have begun to show the appearance of basic motion skills, locomotor and manipulative.

Gallahue states that locomotor basic motion skills, namely: The total body movement in the body is propelled upright posture from one point to the other in a roughly horizontal or vertical direction, movement such walking, running, hopping, galloping, leaping, sliding and jumping [2].

One factor that influences child development is the process of learning in school, Manna explain that physical activity is needed for normal growth and development, and for young people to reach their potential in muscle and bone development [1]. Further, the psychological, social, and physical development process project powerful influences on sport participation. Because, the process of child growth and development will affect their lives in the future. If the child's development escapes the attention of the teacher, especially the teacher (without direction and mentoring the teacher), then the child will grow up according to the attendees and approach them.

Children's motor development is an important aspect of their lives. Saputra states that the principle of motor development is the existence of a change both physically and psychologically in accordance with the period of its growth [3]. Along with the increasing age of a child it will get a lot of things that change in their growth and development with the surrounding environmental conditions.

Regarding the importance of motor development, Zeng at al., explains that early childhood is the most critical and rapid period of complete and healthy motor and cognitive development in human life can provide a motor and cognitive benefits across childhood and adolescence [4]. Therefore, gaining a better understanding of physical activity is a potential in improving motor skills and cognition in young children is critical.

Another thing that affects children's motor development is the environment in which school children. Children who are in a school environment with adequate facilities and infrastructure will be different from children in schools with limited learning facilities. Monnat suggests that School demographic characteristics, including racial/ethnic and socioeconomic 
(SES) composition, class sizes, and rurality may impact schools' abilities to incorporate PA practices into the school day, resulting in disparities that limit children's opportunities to accrue moderate-to-vigorous physical activity (MVPA) [5].

Demographic factors and sports facilities owned by a region or school can influence the type of physical activity carried out by children, besides that it can also foster interest in exercising in children and making children active in carrying out various physical activities and sports. Beurden et al., explain that Child Fundamental Movement Skills (FMS) underpin active lifestyles yet little is known of their distribution and mastery [6].

Fundamental Movement Skills are basic skills that are important for mastered by children, because with the better basic exercise skills possessed by children can make it easier for children to do various movements more complex in sports. concerning the importance of basic sports motion skills, Lubans explains that the mastery of fundamental movement skills (FMS) has been purported as contributing to children's physical, cognitive and social development and is thought to provide the foundation for an active lifestyle [7]. Commonly developed in childhood and subsequently refined into contextand sport-specific skills, they include locomotor (e.g. running and hopping), manipulative or object control (e.g. catching and throwing) and stability (e.g. balancing and twisting) skills.

Based on this explanation, it is important for elementary school-aged children to gain basic movement experience in sports activities, this aims to equip children in gaining mastery of the multilateral movement. Regarding the importance of mastering basic motion, Cowley et al., children's acquisition of fundamental movement skills is essential for children's participation and success in sport [8].

The results of research conducted by Zeng at al. shows that physical activity programs provide young children with the milieu for motor skill development, with motor skills being the foundation for physical activity during early years and subsequent years [4]. Young children today are showing insufficient proficiency in their motor skills.

So it is interesting when this research is to look at the development of children's fundamental movements in the form of abilities such as stability, locomotor, and manipulation of children based on elementary, middle and high school level (initial, elementary, and mature). Gallahue explained that playing facilities can facilitate the development of children's fundamental movements [9]. Play also facilitates cognitive and affective growth in young children and through the medium of play, preschoolers develop a wide variety of fundamental stability, locomotor, and manipulative abilities.

Based on the context above, basic skills with the basic movement skills needed are studied more deeply, as a form of quality analysis, and can also be used as material for physical education and sports in schools.

The hope to be achieved in this study is the realization of proper physical education and sports learning patterns for children, children can grow and develop in accordance with the stages expected, have good quality, maintain children's physical health. Moreover, children will feel happy doing various kinds of sports.

\section{METHOD}

\section{A. Participant}

The research subjects used in this study were students enrolled as students at primary school Cibogo Lembang, sampling was done by cluster sampling technique, which is a sampling technique by taking one of the classes to be sampled. Samples / research subjects, namely: 3rd grade students of primary school Cibogo Lembang, totaling 20 students.

\section{B. Procedure}

The research that the writer did was using descriptive method, because the writer believed that this method was the most appropriate to be applied in this study. In this study, the data obtained was collected, compiled, explained, and analyzed to establish conclusions. The goal is achieved as expected. Therefore the method used in this study is a descriptive expostfacto method.

Regarding this method, Nazir states that: "Ex-postfacto research is a systematic empirical investigation, in which researchers do not have direct control over independent variables because the manifestation of the phenomenon has occurred or because the phenomenon is difficult to manipulate [10].

\section{Instruments}

According to Ali explains that, measurement in the general sense is as a process of determining numbers or numbers in an object or event by following certain rules [11]. So that in order to be able to measure a data, a research instrument is needed that matches the research conducted.

The instrument used in this study is Motor Assessment, which refers to the fundamental movement skills proposed by Gallahue [9]. The basic movement skills that were rolled out by Gallahue there were three basic types of motion capabilities, namely skill stability, local skills, and manipulative skills, and from each movement there were sub-movements included in each category, then each the step has a different level of movement and complexity, which is divided into three stages, namely the early stage, the basic stage and the adult stage [9].

\section{RESULTS AND DISCUSSION}

To give meaning to the results that have been obtained, the next step is to determine the assessment criteria for interpreting the data, using the Norm Reference Assessment, the results are as follows table 1.

TABLE I. RESULTS OF DATA ANALYSIS

\begin{tabular}{|l|l|l|}
\hline \multicolumn{1}{|c|}{ Criteria } & Amount & \multicolumn{1}{c|}{ Percentage } \\
\hline Very well & 1 & $5 \%$ \\
\hline Good & 3 & $15 \%$ \\
\hline Enough & 6 & $30 \%$ \\
\hline Less & 8 & $40 \%$ \\
\hline Very Less & 2 & $10 \%$ \\
\hline
\end{tabular}


Based on table above it can be explained that there is not a significant difference at the elementary level. It can be seen that elementary students who have good fundamental movement skills are only as much as $20 \%$, while for the sufficient category on the movement of fundamental movement skills at elementary level have a movement of fundamental movement skills with enough categories as much as $30 \%$, then for the less category on fundamental motion movement skills at elementary level as much as $50 \%$.

Referring to the data, it can be concluded that it is the average in the category that is not compatible with the stages of child development. the low quality of the basic movements of exercise possessed by children in this study can be caused by several factors, including the lack of physical activity carried out by children both in school and in the neighborhood where they live. Play and exercise habits commonly used by children, have now shifted into passive habits such as playing video games, playing cellphones, social media and watching TV, the results of a study conducted by Nawi $\mathrm{Ng}$ et al., show that the majority of respondents, both men and women, were inactive during their leisure time [12]. thus interfering with motor development and the quality of the basic motion of the sport possessed by the child

Results of research conducted by Falfe et al., results of research conducted by “....in Germany most child and youth sports, both for leisure and competition, is organized in clubs $76 \%$ boys and $59 \%$ girls aged 7 to 14 are doing sports in a club). Schools play only a minor role in offering extracurricular sports activities" [13].

This is due to several factors found that the space available to students is very limited, so that many students who are not actively involved during the learning process take place, regarding the importance of the means, Gallahue explains that "Play also facilitates cognitive and affective growth in young children and through the medium of play, preschoolers develop a wide variety of fundamental stability, locomotor, and manipulative abilities "means play facilities also facilitate cognitive and affective growth in children and through play media, preschool children develop a variety of children's fundamental movements including stability, locomotor and manipulative abilities" [9].

In addition, other factors that cause poor quality of movement of elementary school students are the limited number of class hours, while most students do not have enough free time to do sports activities outside of school hours, while in theory basically, elementary school children are in childhood with an average age of 8-12 years. Gallahue defines at this time, his physical development is at a level where organisms have made it possible to do some basic movements with several variations [9]. The movements carried out during this period are: a) Walking, b) Climbing, c) Jumping, d) Poking, e) Throwing, f) Catching, g) Reflecting the ball, h) Hitting, i) Swimming, and j) Climbing.

Bluma the period of late childhood is the time when motor skills develop the most dynamically, as well as cognitive functions, especially executive ones, which mature around the age of 12 years [14]. Executive functions allow one to engage in a situation through planning a given action, as well as to inhibit or postpone a given reaction. Based on this explanation, for the students, elementary school age requires a wide range of space and is given time to do various kinds of sports movement skills with sufficient duration, so that it can support the physical development, movement and psychic skills of children.

In other words, the factors that make it possible to study it, the results of research conducted by Manna show that maturation and environmental factors influence the progressive development of children and adolescents [1]. By maintaining these principles, young athletes' sports talent can be developed. Therefore, these factors need to be accommodated as part of effective sports skills instruction.

Sports activities and physical activities have a positive influence on improving student learning abilities, and will also make children healthier. By carrying out routine and programmed activities and adjusting to the growth and development of children, it will make children avoid various types of people who lack movement. The results of research conducted by Falfe et al. showed similar results that overall, children's health was significantly better when exercising [13]. Parents value their children's health status significantly better ($0.12 \mathrm{sd}$ ). There is almost no effect on the BMI.

Based on the results of the research, sports activities are important and very needed by early childhood, with the aim to improve the quality of motion that is owned as one of the basis for the development of more complex motor skills in the future. According to Ali, young children's physical activity and motor skill proficiency may be an important predictor of laterlife physically active behaviors [14]. Physical literacy and physical activity interventions within early childhood education could potentially support academic skills as well as physical skills and behaviors. Sports is also a tool to maintain a child's physical health so that children are protected from various diseases at an early age.

\section{CONCLUSION}

Physical education learning in elementary schools must have a multilateral concept in the material taught to students, so that at that time children gain experience and various types of motion skills as a basis for performing a variety of more complex sports skills in later ages.

\section{REFERENCES}

[1] I. Manna, Growth Development and Maturity in Children, 2014.

[2] D. L. Gallahue, "Developmental Physical Education for Today's Children," Indiana University and National Institute for Fitness and Sport. Brown \& Benchmark, 1996.

[3] Y. M. Saputra, "Motor Development and Learning," Bandung: Indonesian Education University, 2010.

[4] N. Zeng, A. Mohammad, S. Haichun, W. Xu, X. Ping and G. Zan, "Effects of Physical Activity on Motor Skills and Cognitive Development in Early Childhood: A Systematic Review," BioMed Research International, Vol 2017, 2017.

[5] S. M. Monnat, "Associations between Demographic Characteristics and Physical Activity Practices in Nevada Schools," Journal HHS Public Access Prev Med. 2017. 
[6] B. Evan, A. Zask, L. M. Barnett and U. C. Dietrich, "Fundamental movement skills How do primary school children perform? The 'Move it Groove it' program in rural Australia," Journal of Science and Medicine in Sport, Volume 5, 2002.

[7] D. R. Luban, "Fundamental Movement Skills in Children and adolencents," Journal Spord Medicine Volume 40, Issue 12, pp 1019_ 1035, 2012.

[8] Cowley, Vicki, J. M. Michael, G. Michael, M. H. Jill and P. Christopher, "Children's fundamental movement skills: are our children ready to play,” BMJ Journal Volume 44, 2010.

[9] D. L. Gallahue and J. C. Ozmun, "Understanding; Motor Development: infants, Children, Adolescents, Adults," The Mc Graw Hill Companies, $4^{\text {th }}$ Edition, Kusmaedi Ruslan, 1998.
[10] M. Nazir, Metode Penelitian, Bogor: Ghalia Indonesia, 2005

[11] M. Ali, Understanding Behavioral and Social Research. Publisher: CV. Ma in Scholar Library, 2011.

[12] Ng. Nawi, "Prevalence of physical inactivity in nine rural INDEPTH Health and Demographic Surveillance Systems in five Asian countries," Journal Glob Health Action. 2009.

[13] Felfe, Christina, L. Michael and S. Andreas, "Sports and Child Development," Journal V, 11 (5), 2016.

[14] I. Bidzan-Bluma and M. Lipowska, "Physical activity and cognitive functioning of children: a systematic review," International journal of environmental research and public health, 15(4) pp800, 2018 